
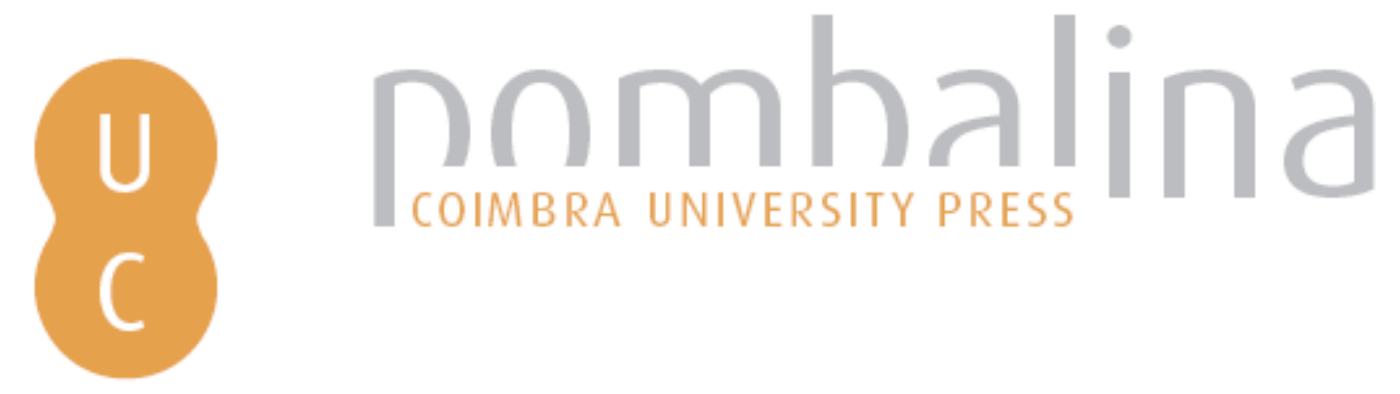

\title{
Era pós-PC: a nova tessitura da narrativa jornalística na web
}

Autor(es): $\quad$ Canavilhas, João; Baccin, Alciane; Satuf, Ivan

Publicado por: Imprensa da Universidade de Coimbra

URL

persistente: URI:http://hdl.handle.net/10316.2/41353

DOI: $\quad$ DOI:https://doi.org/10.14195/978-989-26-1324-6_12

Accessed : $\quad$ 26-Apr-2023 09:29:00

A navegação consulta e descarregamento dos títulos inseridos nas Bibliotecas Digitais UC Digitalis, UC Pombalina e UC Impactum, pressupõem a aceitação plena e sem reservas dos Termos e Condições de Uso destas Bibliotecas Digitais, disponíveis em https://digitalis.uc.pt/pt-pt/termos.

Conforme exposto nos referidos Termos e Condições de Uso, o descarregamento de títulos de acesso restrito requer uma licença válida de autorização devendo o utilizador aceder ao(s) documento(s) a partir de um endereço de IP da instituição detentora da supramencionada licença.

Ao utilizador é apenas permitido o descarregamento para uso pessoal, pelo que o emprego do(s) título(s) descarregado(s) para outro fim, designadamente comercial, carece de autorização do respetivo autor ou editor da obra.

Na medida em que todas as obras da UC Digitalis se encontram protegidas pelo Código do Direito de Autor e Direitos Conexos e demais legislação aplicável, toda a cópia, parcial ou total, deste documento, nos casos em que é legalmente admitida, deverá conter ou fazer-se acompanhar por este aviso. 



\section{ERA PÓS-PC: \\ A NOVA TESSITURA DA NARRATIVA JORNALÍSTICA NA WEB}

João Canavilhas

Universidade da Beira Interior / Labcom.IFP

Alciane Baccin

Universidade Federal do Rio Grande do Sul

Ivan Satuf

Universidade da Beira Interior/Labcom.IFP

\section{Introdução}

A popularização dos dispositivos móveis de comunicação ligados a redes de alta velocidade alterou a forma como se faz e consome informação jornalística. Neste trabalho analisam-se as novas narrativas desenvolvidas para dispositivos móveis, tendo como referências as noções de "tessitura da narrativa" e de "ecossistema mediático".

Se em Portugal a palavra tessitura está associada à música, sendo utilizada para descrever a organização entre os elementos de uma composição, no Brasil refere-se ao ato de produzir tapeçaria numa tela ou o resultado final deste trabalho. 
Embora aplicada em campos diferentes, há um denominador comum aos dois significados - as ligações - por isso pode dizer-se que a tessitura, quando aplicada à narrativa, se refere ao conjunto de ações que ligam elementos num determinado suporte. Numa perspetiva histórica, o jornalismo online sempre esteve vinculado ao computador pessoal (PC). Os conteúdos eram desenvolvidos tendo em consideração os seus limites e potencialidades, mas também as condições de receção que eram razoavelmente conhecidas em termos de espaço e tempo de consumo.

A emergência dos dispositivos móveis fez o termo "online" deixar de ser sinónimo de PC. A narrativa deixou de estar confinada a um suporte específico e espalhou-se por outras plataformas, como smartphones, tablets ou relógios inteligentes, que reconfiguraram as relações espácio-temporais. Esta mudança obriga a pensar em mudanças estruturais na narrativa e na forma como ela se reconfigura dentro de um novo ecossistema mediático. As alterações impõem a necessidade de procurar novas categorias para pensar a narrativa jornalística online num ambiente marcado pela diversidade de suportes.

Com essa finalidade, este trabalho organiza-se em quatro partes. As duas primeiras apresentam a perspetiva ecossistémica dos meios de comunicação e a forma como a evolução do jornalismo na web acompanhou o surgimento de novos elementos tecnológicos. A terceira parte analisa o conceito de tessitura da narrativa para propor a sua integração na nova realidade comunicacional. A última parte apresenta cinco categorias associadas à narrativa online contemporânea: base-de-dados, continuum multimédia, contextualização, imersão e paralaxe/verticalização.

\section{Transformações no ecossistema mediático}

A popularização dos computadores pessoais, juntamente com a emergência da World Wide Web nos anos 1990, expandiram a comunicação 
online para além dos círculos restritos de especialistas. Gradualmente, a internet passou a fazer parte do quotidiano das pessoas comuns, quer no ambiente doméstico quer no local de trabalho.

No período inicial de expansão da web, todos os conceitos estavam fortemente vinculados aos PC: expressões como "interação mediada por computador" ou "comunicação mediada por computador" passaram a ser utilizadas com frequência nos debates sobre as novas práticas sociais (Turkle, 1995; Primo, 2007). A transição entre a vida "on" e "offline" só era possível com o uso do computador pessoal, uma máquina geralmente composta pela integração de CPU $^{120}$, monitor, teclado e rato.

A expansão das redes $w i$-fi de alta velocidade e o surgimento de dispositivos móveis de comunicação alterou decisivamente o panorama da internet no decorrer da primeira década do século XXI. Estes novos aparelhos, com dimensões reduzidas e capacidades computacionais, quebraram a tradicional ligação do consumo online a espaços pré-estabelecidos onde geralmente se colocava o computador pessoal. Hoje não é preciso ter um PC para aceder à Internet e distribuir informação online. Smartphones e tablets criaram um ambiente imersivo que esbate as fronteiras entre o online e o offline. As barreiras tendem a desaparecer numa era em que os meios são ubíquos e estão permanentemente ligados à rede (Deuze, 2012), e a ubiquidade tornou-se mesmo num conceito-chave para entender a comunicação numa era em que as tecnologias estão omnipresentes e facilitam a mobilidade do consumidor.

Neste contexto, vale a pena referir a "falácia da caixa-preta": segundo Jenkins (2006), todo o fluxo mediático passa por um só dispositivo capaz de substituir todos os restantes meios de comunicação. Esta falácia, inicialmente associada aos computadores, está hoje cada vez mais associada às tecnologias móveis, principalmente

\footnotetext{
${ }^{120}$ CPU é a sigla em inglês para Central Processing Unit ou Unidade Central de Processamento, em português.
} 
aos smartphones. O erro central está no facto de analisar a inovação na perspetiva da substituição, considerando que os novos meios integram as funções dos seus antecessores e, por consequência, aniquilam os velhos media.

O desenvolvimento tecnológico não pode ser compreendido como um processo linear caracterizado pela mera substituição de um meio de comunicação por outro, mas como uma intensificação das interações entre meios. Nesta perspetiva, as diferentes formas mediáticas estabelecem relações entre si e a sua adaptação aos novos cenários comunicacionais é uma condição fundamental para a sua sobrevivência. Fidler (1997: 29) recorre às noções de "coexistência e "coevolução" para descrever um complexo sistema adaptativo no qual "à medida que novas formas emergem e se desenvolvem, influenciam, com o passar do tempo e em variados graus, o desenvolvimento de todas as outras formas existentes" ${ }^{121}$.

Bolter e Grusin (2000) desenvolveram o conceito de "remediação" como resposta à abordagem linear do desenvolvimento das tecnologias de comunicação. "O que há de novo sobre os novos meios de comunicação vem das maneiras específicas como estes remodelam os media mais antigos e das maneiras como os media mais antigos se remodelam para responder aos desafios dos novos media"122 (Bolter \& Grusin, 2000: 15). Scolari (2013) chama a este processo "simulação", sublinhando que, enquanto o novo meio tenta criar o seu próprio nicho, o meio antigo luta para sobreviver, usando ambos a mesma estratégia: imitar (ou simular) as características dos meios que o rodeiam.

\footnotetext{
${ }^{121}$ Original: "As each new form emerges and develops, it influences, over time and to varying degrees, the development of every other existing form."

${ }^{122}$ Original: What is new about new media comes from the particular ways in which they refashion older media and the ways in which older media refashion themselves to answer the challenges of new media."
} 
Coexistência, coevolução, remediação e simulação são conceitos que têm uma estreita relação com a Medium Theory, corrente que influenciou os estudos comunicacionais a partir dos anos 1950 e cujos principais expoentes foram Harold Innis e Marshall McLuhan (Meyrowitz, 1994). Innis (2011) propõe uma abordagem "concorrencial" entre os suportes de comunicação que permite observar a intrincada relação entre o substrato físico de cada meio e a perspetiva comunicacional responsável por influenciar a forma como as pessoas comunicam. Defender que os meios concorrem uns com os outros significa assumir a perspetiva relacional em detrimento de modelos de análise que tendem a tratar cada tecnologia de comunicação como uma forma única e alheia ao que o rodeia.

McLuhan (1990: 71) segue o mesmo raciocínio, mas em vez de concorrência, preferiu usar o termo "hibridização", processo em que "todos os meios andam aos pares, um atuando como 'conteúdo' do outro". O cinema, por exemplo, não é um meio autónomo, pois meios anteriores, como a literatura, o teatro e a música, agem como seus conteúdos. Se os meios de comunicação, de facto, funcionam como um sistema de acoplagem, os estudos em comunicação devem optar pela lógica da interdependência dos meios em vez de promoverem análises isoladas.

Neil Postman seguiu a linha de raciocínio de Innis e McLuhan para fundar as bases sobre as quais se ergueu o campo conhecido como Media Ecology. As formulações iniciais estimularam a compreensão das tecnologias comunicacionais a partir da metáfora ecológica importada da biologia. Assim, os meios em constante interação formam um "ecossistema mediático" complexo e em constante transformação. Cada novo meio é descrito como uma "espécie" emergente que se relaciona com outras formas - novas e antigas - numa tentativa conjunta de reestabelecer o equilíbrio de todo o sistema.

A comunicação contemporânea é marcada, portanto, pela divergência do hardware e a simultânea convergência dos conteúdos (Jenkins, 
2006), ou seja, há mais aparelhos que servem como pontos de passagem nas trocas comunicacionais e a vida online é marcada pela manipulação constante das diferentes tecnologias de conexão. Canavilhas (2011) sugere que os conteúdos devem ter em consideração um elevado grau de contextualização resultante da personalização do consumo e da mobilidade, capacidade proporcionada pelas redes digitais.

As duas mudanças principais nos fatores contextuais são uma consequência da entrada da internet e dos dispositivos móveis no ecossistema mediático: falamos da individualização do consumo e da mobilidade. Através de computadores pessoais, plataformas de jogos, PDA ou telefones móveis, os consumidores mudaram os seus padrões de consumo mediático, que passaram de contextos grupais a contextos individuais, e de espaços pré-determinados a qualquer lugar onde há uma rede móvel. ${ }^{123}$ (Canavilhas, 2011: 19).

Neste novo ambiente fortemente marcado pela ubiquidade, mobilidade e consumo individual, consequência da popularização dos dispositivos móveis ligados a redes de alta velocidade, o surgimento de novas narrativas online acaba por ser uma consequência natural.

\section{Evolução da narrativa jornalística na web}

Há mais de 20 anos, momento em que o jornalismo começou a crescer na internet, surgiu um desafio: como consolidar um novo meio que

\footnotetext{
123 Original: "Los dos cambios principales en los factores contextuales son una consecuencia de la entrada de Internet y de los móviles en el ecosistema mediático: hablamos de la individualización del consumo y de la movilidad. A través de ordenadores personales, plataformas de juegos, PDAs o teléfonos móviles, los consumidores cambiaron sus patrones de consumo mediático, que han pasado de contextos grupales a contextos individuales, y de espacios predeterminados a cualquier lugar donde haya una red móvil."
} 
parecia juntar os meios anteriores? As primeiras iniciativas jornalísticas na internet não trouxeram nenhuma novidade, mas a dinâmica própria da web não tardou: desde maio de 1993, momento em que apareceu o primeiro jornal com versão online (San Jose Mercury News) ${ }^{124}$ até ao atentado contra as Torres Gémeas, em 11 de setembro de 2001, passaram menos de 10 anos, mas foi o suficiente para o jornalismo se estabelecer definitivamente no ambiente web (Katz, 2001; Zelizer, Allan, 2002; Ferrari, 2003; Malini, 2009; Migowski, 2013).

Ao longo das últimas décadas, o jornalismo na web tem estado em constante transformação nos campos da produção, distribuição e consumo. Dentro da produção, este trabalho centra-se especificamente nas adaptações verificadas no campo da narrativa jornalística. Desde os primeiros anos, são muitas as etapas percorridas pelo jornalismo na Web na tentativa de desenvolver produtos adequados ao meio, procurando desta forma comunicar de maneira mais eficiente com o público. Essas etapas foram estudadas por vários investigadores como Cabrera Gonzalez (2000), Pavlik ${ }^{125}$ (2005), Pryor ${ }^{126}$ (2002), Palacios (2002), Mielniczuk (2003), Barbosa $(2007,2013)$ que procuraram traçar um percurso do jornalismo na web. Embora com algumas diferenças de pormenor, as propostas têm muitos pontos em comum: neste trabalho parte-se da proposta de três gerações do jornalismo na web

\footnotetext{
${ }^{124} \mathrm{O}$ autor admite que outros jornais possam ter surgido antes na internet, mas o San Jose Mercury News foi o primeiro a colocar todo o conteúdo da edição online.

${ }^{125}$ John Pavlik (2005) propõe uma sistematização em três fases do jornalismo na web, tendo como foco a produção de conteúdos. Na primeira, predominam os sites jornalísticos que publicam material editorial produzido para outros meios, os quais o autor denomina de "modelo-mãe". Na segunda fase, dá ênfase aos conteúdos originais produzidos para o online, com o uso de links. Já a terceira fase caracteriza-se pela produção de conteúdos noticiosos originais e que utilizam recursos multimédia, pensados e desenvolvidos especificamente para o novo meio - a web, proporcionando o jornalismo contextualizado no qual se experimentam novas formas de storytelling. ${ }^{126}$ Pryor (2002) destaca a existência de três vagas: a primeira vaga (a partir de 1982) caracteriza-se pela utilização do videotexto para a disseminação de informações; a segunda (1993) com o surgimento da web e dos primeiros fornecedores de acesso à Internet (ISP); a terceira (2001) distingue-se pelo desenvolvimento, especialização e sofisticação das empresas, da tecnologia disponível e dos profissionais.
} 
elaborada por Mielniczuk (2003), acrescentando-se as duas propostas por Barbosa $(2007,2013)$.

Primeira Geração (fase da transposição): o conteúdo jornalístico dos webjornais é uma cópia do conteúdo do jornal em papel. A publicação segue a lógica do impresso, com atualização a cada 24 horas. Para Mielniczuk (2003: 32), foi "muito interessante observar as primeiras experiências realizadas: o que era chamado então de 'jornal online', na web, não passava da transposição de uma ou duas das principais matérias de algumas editorias". Como nesta fase não há nenhuma preocupação em explorar as potencialidades do novo meio, o modelo narrativo é igual ao do jornalismo impresso: a única preocupação é ter uma presença no ambiente web.

Segunda Geração (fase da metáfora): os produtos ainda lembram o jornalismo impresso, mas começam a surgir experiências hipertextuais e atualizações mais frequentes, afastando-se assim do modelo de 24 horas do papel. Mielniczuk (2003) também se refere ao uso do correio eletrónico como possibilidade de interação entre jornalistas e leitores e de chats ou fóruns de debates para interação entre os próprios leitores. Segundo a autora, "ao mesmo tempo em que se ancoram no modelo do jornal impresso, as publicações para a web começam a explorar as potencialidades do novo ambiente, tais como links com chamadas para notícias de factos que acontecem no período entre as edições" (Mielniczuk, 2003: 34).

Terceira Geração (fase do webjornalismo): as potencialidades do jornalismo na web começam a ser exploradas de maneira mais efetiva, em parte graças à melhoria das condições tecnológicas para produção e disseminação dos conteúdos jornalísticos. Inicia-se um período em que as instituições jornalísticas vislumbram a possibilidade de oferecerem um produto diferente do que é oferecido pelo impresso. De acordo com Mielniczuk (2003: 36), "nos produtos jornalísticos dessa etapa, é possível observar tentativas de, efetivamente, explorar e aplicar as potencialidades oferecidas pela web para fins 
jornalísticos". Nesta geração surgem novas narrativas jornalísticas graças ao aproveitamento de características do jornalismo na web, como a multimedialidade, a interatividade, a hipertextualidade, a atualização contínua, a memória e a personalização (Bardoel \& Deuze, 2001; Palacios, 2002; Canavilhas, 2014).

Quarta Geração (fase Jornalismo Digital em Bases-de-Dados): o desenvolvimento do jornalismo na web assenta na exploração das bases-de-dados, que passam a influenciar o processo jornalístico na produção, edição, formato de produtos, construção de narrativas hipermédia, experimentação com novos géneros jornalísticos e visualização das informações. Segundo Barbosa, o recurso às bases-de-dados condicionou sempre a inovação "seja atendendo aos propósitos de armazenamento das informações para recuperação e compartilhamento (...) seja para atender às necessidades colocadas para a publicação das edições digitais dos jornais." (Barbosa, 2007: 124)

Estas possibilidades de utilização das bases-de-dados também foram salientadas por Manovich (2006): segundo o autor, são elas que sustentam a construção de narrativas diversificadas no ambiente digital. É ainda nesta geração que a utilização das bases-de-dados apresenta convergência nos modelos narrativos e que as inovações tecnológicas, tanto na produção como na distribuição dos conteúdos jornalísticos, proporcionam o aparecimento de "formatos e/ou géneros emergentes próprios do meio digital" (Larrondo, Mielniczuk \& Barbosa, 2008).

Quinta Geração (fase da medialidade ${ }^{127}$ e das bases-de-dados): as bases-de-dados tornam-se ainda mais presentes no processo de estruturação do jornalismo na web e na convergência dos meios. O Jornalismo Guiado por Dados ou Data Journalism (Barbosa \& Torres, 2013) e os meios móveis surgem como agentes impulsionadores da inovação, "no qual a emergência dos chamados aplicativos

\footnotetext{
${ }^{127}$ Centralidade dos meios na comunicação e nas experiências humanas.
} 
jornalísticos autóctones para tablets são produtos paradigmáticos" (Barbosa, 2013). As características do paradigma do jornalismo de bases-de-dados são a medialidade (pela via da convergência), horizontalidade (no processamento dos fluxos de informações entre as plataformas), continuum multimédia (integração de processos e produtos), meios móveis, aplicações (apps) e produtos autóctones. Pelo menos 5 das mais de 20 funcionalidades das bases-de-dados referem-se às narrativas jornalísticas:

1) integrar os processos de apuração, composição, documentação e edição dos conteúdos; 2) orientar e apoiar o processo de apuração, coleta, e contextualização dos conteúdos; 3) regular o sistema de categorização e qualificação das distintas fontes jornalísticas, indicando a relevância delas; 4) habilitar o uso de metadados para análise de informações e extração de conhecimento, por meio de técnicas estatísticas ou métodos de visualização e exploração como o data mining7. Também assegurando a aplicação da técnica do tagging8; e 5) garantir a flexibilidade combinatória e o relacionamento entre os conteúdos (Barbosa \& Torres, 2013: 154).

A massificação dos dispositivos móveis gerou um novo processo de compreensão jornalística, isto é, os tablets e smartphones obrigaram a uma reconfiguração dos processos jornalísticos nas redes digitais. Para Barbosa (2013: 33), "o cenário atual é de atuação conjunta, integrada, entre os meios, conformando processos e produtos" e os bancos de dados, a medialidade e o continuum multimédia passam a ser determinantes e reconfiguradores das formas de narrar no jornalismo online.

As sistematizações propostas por Mielniczuk (2003) - da primeira à terceira geração - e por Barbosa $(2007,2013)$ - na quarta e na quinta gerações - podem coexistir num mesmo site jornalístico, pois não se referem a processos datados e estanques. 


\section{Tecendo a estrutura da narrativa jornalística na web}

A analogia entre o "ato de tecer um tecido" e a "tessitura da narrativa jornalística" foi feita anteriormente pelos investigadores Cremilda Medina e Paulo Roberto Leandro num livro de 1973 intitulado "A arte de tecer o presente: jornalismo interpretativo". Ao discutirem uma teoria da interpretação, os autores salientam que não basta informar, é preciso contextualizar. A simplificação do ato de informar pode transformar o jornalismo num mero ato burocrático pelo que só a contextualização permite uma narrativa criativa e inovadora. Mas como ocorre essa tessitura da narrativa jornalística neste novo ecossistema marcado pela mobilidade e pela ubiquidade?

Considerando-se que a tessitura da narrativa se refere ao conjunto de ações que ligam vários elementos, construindo um tecido narrativo entre os suportes, pretende-se demonstrar que o jornalismo na web tem criado formas inovadoras para aproveitar as possibilidades que os novos meios proporcionam aos jornalistas.

Tal como foi anteriormente referido, o jornalismo na web começou por estar ligado ao computador. Por isso, a tessitura da narrativa nas primeiras gerações do jornalismo na web foi pensada dentro dos limites impostos pelos computadores pessoais, fossem eles portáteis ou de secretária. Considerando a emergência de um novo ecossistema mediático, e as características detalhadas por Barbosa (2013) na quinta geração do jornalismo na web, coloca-se o desafio da superação, isto é, de pensar a tessitura sobre uma trama que se adapte aos dispositivos móveis.

Antes disso é preciso refletir sobre o momento em que ocorreram as mudanças na estrutura da narrativa jornalística na web. É justamente na terceira geração do jornalismo na web (Mielniczuk, 2003) que o hipertexto passa a ser um elemento preponderante na construção da notícia, tornando-se no elemento central da narrativa. Essa geração coincide com a terceira fase do jornalismo na web identificada igualmente por 
Pavlik (2005) e Cabrera Gonzalez (2000), destacando-se a importância das experimentações com novas formas de narrar factos (storytelling). Este momento é marcante porque até esse momento usava-se a narrativa da imprensa tradicional resumida a "textos que informam, mas não empolgam, muito menos motivam. Não mobilizam a adesão e participação dos leitores ou conseguem resultados pífios" (Lima, 2014: 123). Esta transposição de conteúdos do impresso, o chamado shovelware, é apontado ainda hoje como uma das razões para a crise do jornalismo, ao ter causado um empobrecimento da narrativa e frustrado as expectativas dos leitores em relação ao potencial do meio (Neveu, 2014).

Com o hipertexto abriram-se novas possibilidades de inovação narrativa para o jornalismo feito na web. A hipertextualidade (Landow, 1997, 2009; Mielniczuk, 2003; Canavilhas, 2014 ; Mielniczuk et al., 2015) é uma das características fundamentais na exploração do potencial oferecido pela web. Ao proporcionar a ligação entre blocos de informações por meio de links, o hipertexto permite ao utilizador um consumo noticioso personalizado com um simples clique. Este poder conferido ao utilizador desencadeia ações que permitem uma maior e mais profunda interação com a plataforma. A hipertextualidade, em conjunto com a multimedialidade e a interatividade, facilitam a produção de narrativas convergentes e imersivas que, aliadas à memória e à personalização, permitem ainda incrementar a contextualização dos factos, valorizando elementos que fortalecem as narrativas de aprofundamento

Investigadores de diversas áreas, como as artes (Manovich, 2006), a literatura (Murray, 2003; Ryan, 2004), o entretenimento (Jenkins, 2006) ou os jogos (Brown, Cairns, 2004), defendem a necessidade de se criarem estórias utilizando meios diferenciados e tecnologias contemporâneas. No jornalismo estas iniciativas têm sido desenvolvidas a título experimental, algumas das quais com grande êxito. É o caso da reportagem "Snow Fall" do The New York Times, publicada em 2012, que foi considerada um modelo desta estrutura narrativa 
pela estória relatada, mas sobretudo porque as modalidades comunicativas $^{128}$ (Canavilhas \& Baccin, 2015) foram bem integradas na narrativa e contribuíram para a contextualização do acontecimento. O sucesso foi tão grande que os jornalistas norte-americanos, quando na posse de uma boa estória, passaram a perguntar: can we "snowfall" this? (Dowling \& Vogan, 2014; Sullivan, 2013). Canavilhas (2014a) faz uma análise de 1155 comentários dos leitores de Snow Fall e constata que 798 fazem referência às características da reportagem, destes $98 \%$ avaliaram positivamente o trabalho e destacaram a qualidade e originalidade da narrativa multimediática. "Mais do que uma metamorfose ou uma remediação, este trabalho é um bom exemplo de diferenciação do webjornalismo em relação aos jornalismos dos meios anteriores, sendo bem visíveis alguns elementos de rutura" (Canavilhas, 2014a : 126). Os elementos que causaram uma rutura com os modelos narrativos anteriores foram a verticalização da narrativa, a autonomização do vídeo em formato sincrónico e a forma como os conteúdos multimédia são integrados no texto. No entanto, o autor sublinha que esta linguagem se aplica sobretudo a géneros longos, como a reportagem. O jornalismo longform (Sharp, 2013; Longhi, 2014, 2015; Tenore, 2014) é uma evolução da narrativa jornalística web e com ela "surge um ponto de virada em relação aos produtos na forma de especiais multimídia que dominaram até então, nos quais o texto, geralmente longo, era tratado e disponibilizado na forma de fragmentos" (Longhi, 2014: 912). A autora acrescenta que o jornalismo longform também se caracteriza por narrativas textuais mais consistentes e formas inovadoras relativas ao design, à navegação e à imersão do utilizador.

\footnotetext{
128 "Por modalidades comunicativas entendem-se todos os recursos utilizados para facilitar e melhorar a compreensão dos acontecimentos relatados nas reportagens, podendo ser texto escrito, áudio, vídeo, fotografias, animações ou infográficos" (Canavilhas \& Baccin, 2015). Esta expressão, adaptada da obra de John Pavlik (2005), salienta que o relato interativo inclui uma ampla gama de modalidades de comunicação, como o texto, as imagens, os vídeos e os gráficos.
} 


\title{
As potencialidades do tecido hipernarrativo
}

No atual ecossistema mediático, a narrativa jornalística deve assumir formas inovadoras e explorar todas as suas potencialidades. Numa sociedade complexa, os acontecimentos não se desenrolam de maneira isolada e, por isso, requerem narrativas ampliadas, rigorosas e contrastadas que só encontram resposta num "jornalismo sistema”:

\begin{abstract}
apostar em um jornalismo sistema é desenvolver um jornalismo que não desuna os acontecimentos; que os contemple e os articule em um contexto determinado e que estabeleça uma gama de interações com os recetores que possa contribuir com a construção do sentido e a compreensão da realidade (Fontcuberta \& Borrat, 2006: 41).
\end{abstract}

De acordo com este modelo de jornalismo, a hipernarrativa ${ }^{129}$ no webjornalismo de quinta geração procura ligar os conteúdos, articulá-los e explicá-los, integrando os factos num determinado contexto que facilita a sua compreensão. A hipernarrativa tem suficiente flexibilidade para estabelecer variações no desenho da informação sem que se percam os significados. Por isso, neste trabalho é analisada a construção da hipernarrativa e são destacadas algumas potencialidades que ela apresenta, nomeadamente bases-de-dados, continuum multimédia, contextualização, imersão e verticalização.

Bases-de-dados: Segundo Barbosa (2004), são entendidas como uma metáfora do jornalismo da web, pois elas representam a forma cultural simbólica que diferencia o online do impresso. Neste

\footnotetext{
129 Para Manovich (2006), as bases-de-dados são responsáveis por uma nova definição de narrativa, a hipernarrativa, que resulta da soma das trajetórias efetuadas através das bases-de-dados. Adota-se este termo porque se identifica a base-de-dados como uma potencialidade da narrativa no ambiente online.
} 
trabalho usa-se igualmente esta potencialidade como metáfora de um jornalismo caracterizado pela organização complexa que inclui os processos de armazenamento, disponibilização, apresentação e consulta dinâmica da informação. A utilização de bases-de-dados e de modelos inovadores de visualização da informação possibilita o surgimento de novas formas de narrar os factos e de formatos noticiosos mais dinâmicos. Para Machado, a "narrativa, em vez de uma sucessão de ações, configura-se cada vez mais como uma viagem através do espaço constituído pelos conjuntos estruturados de itens organizados na forma base de dados e torna-se um conjunto contínuo de ações narrativas e explorações" (2006: 50). De acordo com o autor, o fluxo dos novos modelos de narrativa jornalística incorpora e depende diretamente da intervenção do utilizador/leitor.

Bradshaw (2012) procurar diferenciar o jornalismo de dados (data journalism) do jornalismo tradicional. Segundo este autor, a resposta pode estar nas novas possibilidades resultantes da união entre o tradicional "faro jornalístico" e a capacidade de contar uma estória envolvente recorrendo aos muitos dados existentes sobre cada tema.

Um bom exemplo do recurso às bases-de-dados é a reportagem "Bicho de Sete Cabeças ${ }^{130 "}$ (Fig. 1), da Agência Pública, publicada em 16 de abril de 2014. A reportagem refere-se às transferências de recursos federais para a educação nas cidades que receberam jogos do Campeonato Mundial de Futebol no Brasil, em 2014. De acordo com os jornalistas, que tiveram acesso aos dados da Matriz de Responsabilidades do "Ministério do Esporte" e ao "Portal da Transparência”, mantidos pela Controladoria-Geral da União (CGU), os números dos dois órgãos Federais são divergentes. Na reportagem, as bases-de-dados fornecem informação para a reportagem e contribuem para a estrutura da narrativa, pois os leitores podem ter acesso direto aos dados. A reportagem descobriu que não existe uma

\footnotetext{
${ }^{130} \mathrm{http} / / /$ apublica.org/2014/04/bicho-de-sete-cabecas/
} 


\section{Bicho de sete cabeças}

Depois de dois meses de tentativas, governo nāo explica divergência nos dados entre MEC e CGU sobre repasses da verba de educaçâo nas cidades-sede da Copa; entenda os limites da transparência

Em janeiro, a Pública fez uma reportagem baseada em dados incompletos sobre repasses federais à educação nas 12 cidades-sede da Copa do Mundo. Foi um erro, já admitido em um editorial na época. Entre outras coisas, nosso infográfico comparava os valores dos financiamentos a estádios aos repasses federais em educação para cada cidade. Os valores tinham como base a Matriz de Responsabilidades do Ministério do Esporte e o Portal da Transparência, mantido pela Controladoria-Geral da União (CGU).

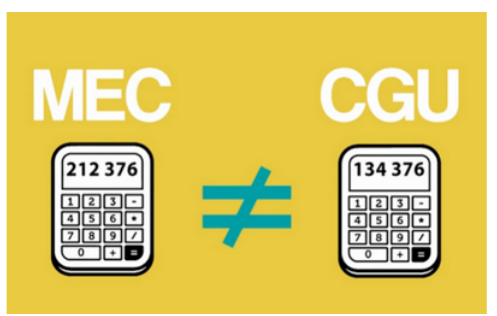

Fig. 1 - Exemplo da potencialidade "bases-de-dados" na narrativa Fonte: http://apublica.org/2014/04/bicho-de-sete-cabecas/

base-de-dados única nem uma norma nacional para contabilizar as transferências de verbas Federais para educação. O trabalho mostra a saga que é encontrar dados fidedignos e a dificuldade para entender este "bicho de sete cabeças".

Contextualização: Os meios online têm um grande potencial de contextualização ao possibilitarem o aprofundamento do tema e o estabelecimento de relações entre temáticas, por não terem limites de tempo/espaço. De acordo com Pavlik (2005), o jornalismo contextualizado reúne cinco aspetos: a) a ampliação das modalidades de comunicação (texto, áudio, vídeo, fotos, gráficos, animação); b) o hipermédia (que permite situar a notícia em contextos históricos, políticos e culturais muito mais ricos); c) a participação cada vez maior dos leitores/utilizadores, que necessitam interagir com 
a máquina ("uma das maneiras de aumentar a participação é o relato imersivo 131") (Pavlik, 2005: 48); d) os conteúdos mais dinâmicos (conteúdos informativos mais fluidos); e) a personalização da informação (cada leitor/utilizador pode filtrar a informação que quiser e ampliar as informações que a reportagem lhe oferece). No webjornalismo, "todas as modalidades da comunicação humana se encontram à nossa disposição para contar estórias da forma mais atrativa, interativa e o mais possível de acordo com seu pedido ${ }^{132}$ " (Pavlik, 2005: 44).

De acordo com os cinco aspetos apontados pelo autor, a contextualização só é possível graças às bases-de-dados que permitem a ampliação das modalidades de comunicação, o hipermédia, a participação de leitores/utilizadores, os conteúdos informativos mais fluidos e a personalização da informação. Outra grande contribuição das bases-de-dados para a contextualização é a possibilidade de memória, que torna possível a integração de outros produtos jornalísticos ou documentos.

Vários aspetos do jornalismo contextualizado podem ser identificados na reportagem "The new cold war" (Fig. 2) sobre a exploração de petróleo no Alaska, publicada no jornal The Guardian, em junho de 2015. O trabalho utiliza todas as modalidades comunicativas (texto, vídeo, áudio, fotografias, infográficos), situa a informação no texto social, ambiental e político, o relato é imersivo e os conteúdos são fluidos e dinâmicos. A reportagem aborda a concessão dada pelo governo norte-americano à Shell para explorar uma das maiores reservas de petróleo do mundo, as consequências ambientais e a possível extinção da população local.

\footnotetext{
${ }^{131}$ Original: "Una de las maneras para aumentar la participación es el relato inmersivo". ${ }^{132}$ Original: "todas las modalidades de la comunicación humana se encuentran a nuestra disposición para contar las historias más atractiva, interactiva, a petición y a medida posible".
} 


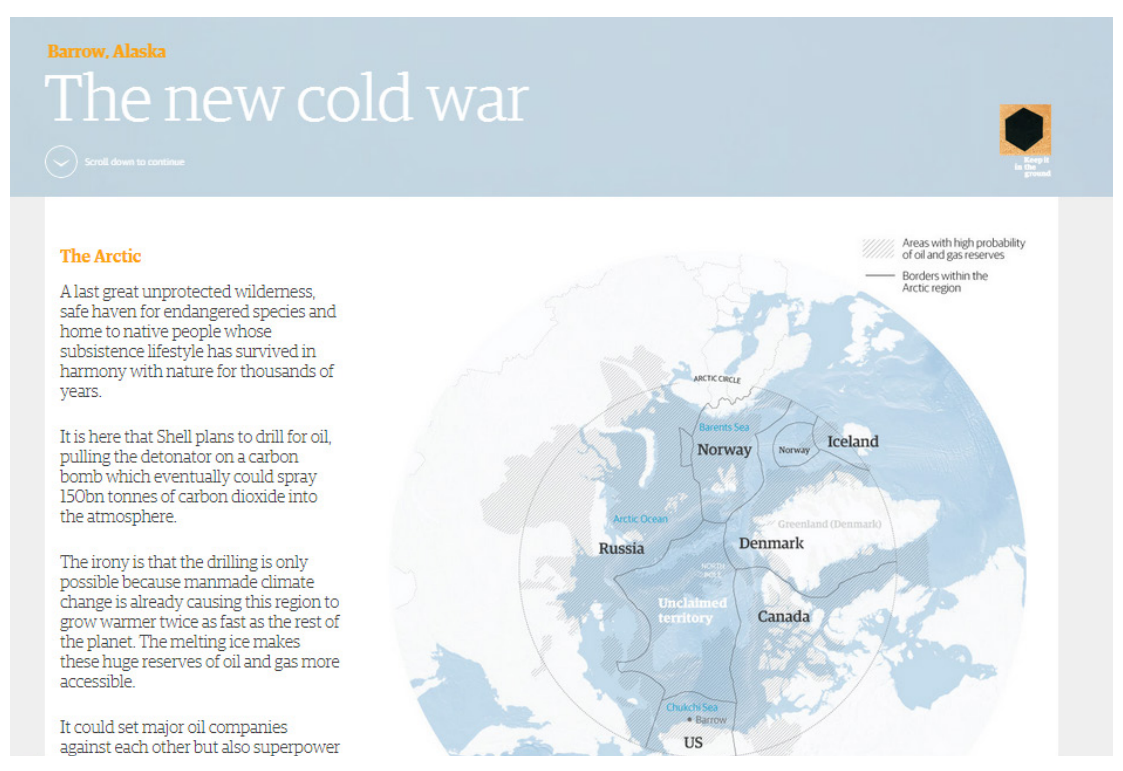

Fig. 2 - Exemplo da potencialidade "contextualização" na narrativa Fonte: http://www.theguardian.com/environment/ng-interactive/ 2015/jun/16/drilling-oil-gas-arctic-alaska

Imersão: A imersão relaciona-se com a contextualização porque é ela que permite a sensação de estar imerso. Com a humanização das narrativas, o leitor é convidado para uma imersão que pode ocorrer em vários sentidos (simbólica, psicológica, racional, emocional). O leitor "é estimulado a captar a realidade e senti-la, porque o grande propósito condutor é dar-lhe elementos para compreender a situação abordada de uma maneira muito mais rica e infinitamente menos rasa do que o texto meramente informativo é capaz de oferecer" (Lima, 2014: 121).

A partir do conceito de imersão nos jogos, Nonny de la Peña (2010) acredita que o jornalismo de imersão é um novo género que utiliza plataformas de jogos e ambientes virtuais para transmitir 


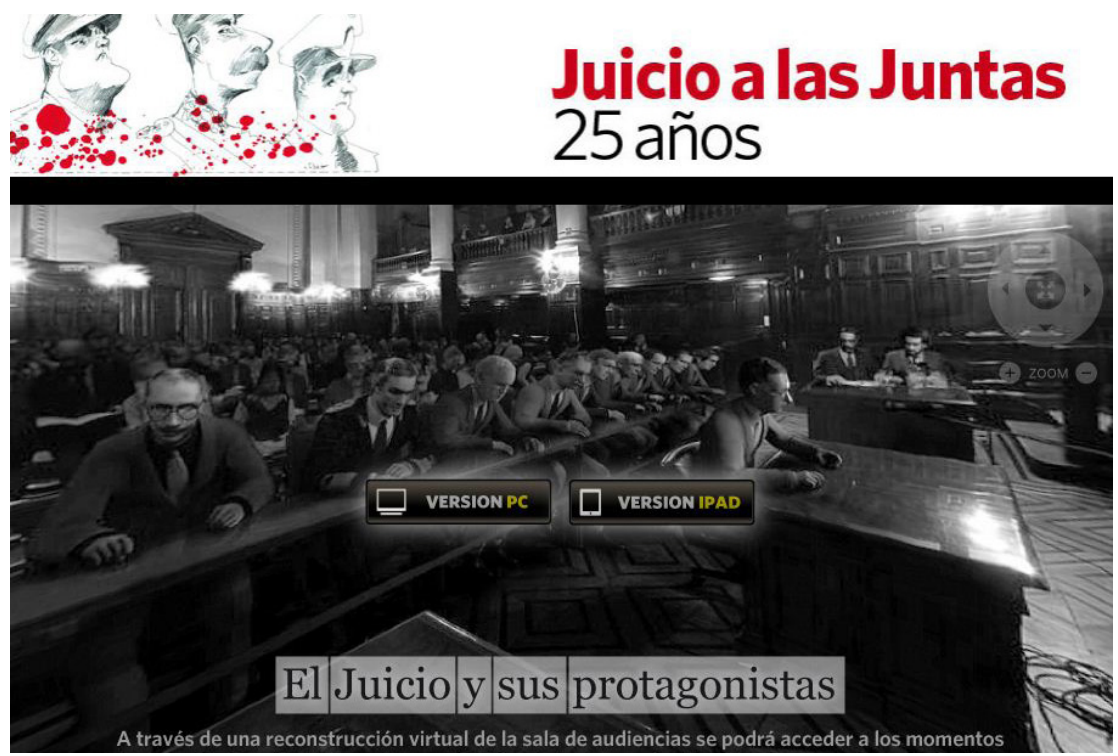

Fig. 3 - Exemplo da potencialidade "imersão" na narrativa Fonte: www.clarin.com/la-sala

notícias, documentários e estórias de não-ficção. "A ideia fundamental do jornalismo de imersão é possibilitar que o usuário realmente entre no cenário que praticamente recria a notícia e a experimente" (Mielniczuk, 2015: 134).

Um exemplo de imersão é a reportagem "La sala del juicio" (Fig. 3), publicada em dezembro de 2010 pelo jornal argentino El Clarín. A reportagem reconstrói virtualmente, 25 anos depois, o histórico julgamento dos militares envolvidos na ditadura argentina. O leitor da reportagem pode movimentar-se dentro da sala do tribunal, escolher qual o ângulo de visão da sala, clicar nas imagens de cada personagem do julgamento para obter mais informações e ainda selecionar sons sobre os depoimentos. 


\section{PILOTE O FOLHACÓPTERO}

\section{Aplicativo permite explorar a usina de Belo Monte}

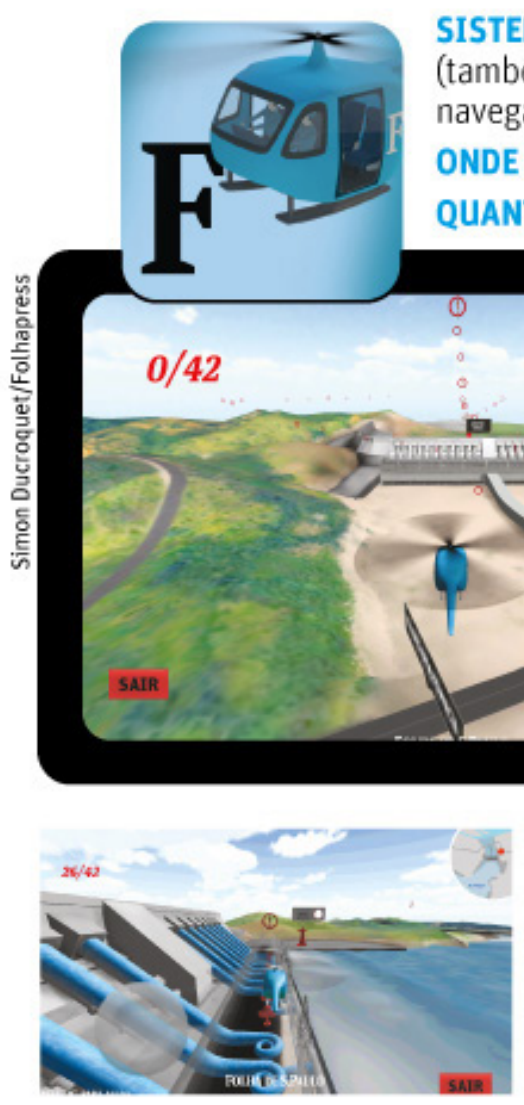

SISTEMA Android e iOS

(também acessível pelo

navegador)

ONDE bit.ly/folhacoptero

QUANTO Gratuito

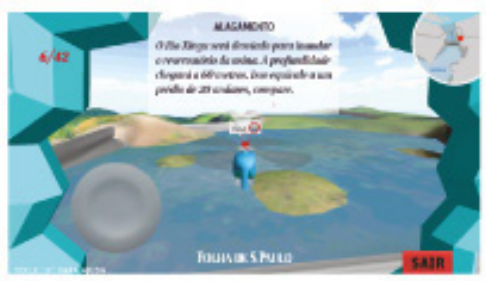

CONTROLE 0 jogador pode pilotar, em modo livre ou automático, 0 Folhacóptero e sobrevoar a área de construção da usina

PONTOS Coleta de anéis vermelhos valem pontos e dicas sobre como usina funciona e quais são seus impactos

Fig. 4 - Exemplo da potencialidade "continuum multimédia" na narrativa Fonte: http://arte.folha.uol.com.br/especiais/2013/12/16/folhacoptero/ 
Continuum multimédia: A quinta geração do jornalismo digital desenvolve-se num cenário de convergência jornalística, no qual "a lógica não é de dependência, competição ou de oposição entre os meios e seus conteúdos em diferentes suportes, característica de etapas anteriores do jornalismo" (Barbosa, 2013: 33). A convergência possibilita o continuum multimédia, pois é por meio dela que a narrativa se expande nos vários meios, possibilitando uma melhor compreensão do contexto narrativo. Os vários meios atuam em conjunto, integrando processos e produtos nos quais os fluxos de produção, edição e distribuição dos conteúdos são horizontais e expansíveis.

O jornal Folha de S. Paulo criou, em 2013, o "Folhacóptero" (Fig. 4) para explicar a construção da usina de Belo Monte, no Estado do Pará (Brasil). Na reportagem existe um ícone que permite fazer o download da aplicação e voar sobre a informação. Depois dessa reportagem, que foi a primeira da série "Tudo Sobre", a Folha já utilizou esta técnica noutras narrativas jornalísticas. A aplicação permite uma imersão mais profunda na narrativa, transportando o leitor/utilizador para o ambiente da reportagem. Neste caso, a imersão é potencializada pelo continuum multimédia.

Paralaxe/Verticalização: Até à publicação de Snow Fall, o design e a estrutura visual das narrativas seguiam a lógica dos meios anteriores, com a justaposição de textos, imagens e sons e seções fragmentadas. Snow Fall inova com a introdução da verticalização da narrativa. De acordo com Barbosa, Normande e Almeida (2014: 11), "podemos verificar uma grande diferenciação das narrativas até então publicadas na web: a dimensão das páginas a partir do design verticalizado, mais comum nos produtos autóctones, com aproximadamente 604 pixels de altura”. Canavilhas $\left(2014^{a}\right)$ alarga a discussão desta potencialidade para lá da simples arquitetura da notícia, chamando "reportagem paralaxe" às narrativas que, para além de utilizarem a tecnologia parallax scrolling, apresentam "navegação 


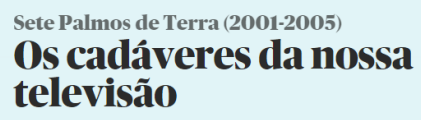

FPEDERICD EATISTA, SIB LLA LND, ANDPEA ESPADNHA \& DINIS CORPELA Os Fisher começaram a despedir-se a 6 de Junho de 2005, há uma década, na estreia da quinta e última temporada da série da HBO. A despedir-se e morrer, como morremos todos "Ninguém fica." Os fass sabiann-no, como sabemos todos, mas nao estavam preparados. E choraram - a morte das personagens e, com isso, dos familiares, dos amigos, a sua própria morte. Estamos prontos para uma visita.

Uma década depois do fim, que morte é esta?

Nunca a morte ficou táo bem a una série. Voltámos à obra de Alan Ball, à cave onde se embelezavam cadáveres para libertar o luto.

Fig. 5 - Exemplo da potencialidade paralaxe/verticalização da narrativa Fonte: http://www.publico.pt/culturaipsilon/noticia/uma-decada-apos-o-fim-dos-sete-palmos-de-terra-que-morte-e-esta-1697938

verticalizada e intuitiva, em conjunto com a plena integração de conteúdos multimédia" tornando "a leitura mais imersiva e envolvente, não requerendo ao utilizador conhecimentos de informática muito profundos" (2014 a : 123).

Essa potencialidade rompe com um modelo até aqui convencional nas narrativas web e imprime um design pensado para os dispositivos móveis. O modelo paralaxe/vertical passou a ser adotado por jornais de todo o mundo, que encontraram em Snow Fall um exemplo a ser seguido. Barbosa, Normande e Almeida acrescentam ainda que "a inovação trazida, inicialmente, por 'Snow Fall' e, posteriormente, pelas narrativas que se seguiram resulta do emprego das bases de dados e de suas funcionalidades no jornalismo em redes digitais" (2014: 17).

A narrativa paralaxe/vertical tornou-se num formato modelo para grandes reportagens. O jornal Público utiliza-o para abordar temas variados: na reportagem sobre os 10 anos de encerramento da série da HBO, "Sete Palmos de Terra", o jornal publicou a reportagem “Os cadáveres da nossa televisão” (Fig. 5), abordando 
as mortes que aconteceram no final da série e relembrando partes emocionantes dos episódios. A narrativa é totalmente vertical e à medida que o leitor/utilizador utiliza o scroll, os vídeos começam automaticamente.

Estes cinco exemplos mostram que as tessituras narrativas no novo ecossistema mediático se afastam definitivamente dos modelos tradicionais anteriores, tornando-se mais envolventes, imersivos e contextualizados. Deve ser referido que as categorias aqui apresentadas não esgotam as novas possibilidades de apresentação de conteúdos jornalísticos. Em todo o mundo são feitas experiências com narrativas desenvolvidas especificamente para dispositivos móveis (Canavilhas \& Satuf, 2013; Bertocchi, Camargo \& Silveira, 2015) que em breve poderão vir a ter uma utilização mais alargada e intensa, tal como aconteceu com as potencialidades estudadas.

\section{Considerações finais}

A popularização dos dispositivos móveis e as mudanças verificadas nos hábitos de consumo obrigaram o jornalismo a procurar narrativas que explorem o potencial deste novo ecossistema mediático. As cinco categorias aqui descritas - bases-de-dados, continuum multimédia, imersão, contextualização e paralaxe/verticalização - são exemplos de respostas a um ecossistema marcado pela ubiquidade e pela mobilidade.

Neste ecossistema, a produção de conteúdos exige criatividade e conhecimentos técnicos que permitam elaborar hipernarrativas capazes de atrair a atenção do leitor/utilizador. O jornalista, tal como um alfaiate, deve ser capaz de costurar com perfeição os diversos elementos que fluem rapidamente de um meio para o outro, elaborando uma boa tessitura da narrativa. 


\section{REFERÊNCIAS BIBLIOGRÁFICAS}

BARBOSA, S. (2004). "Banco de dados como metáfora para o jornalismo digital de terceira geração", in VI Lusocom, III Sopcom, II Ibérico, 2004, Covilhã. Ciências da Comunicação em Congresso na Covilhã. III Sopcom, VI Lusocom, II Ibérico, UBI. Covilhã - Portugal: Universidade da Beira Interior. Available from: <http:// www.bocc.ubi.pt/pag/barbosa-suzana-banco-dados-metafora-para-jornalismo-digital-terceira-geracao.pdf > Accessed: 26 jun 2015

BARBOSA, S. (2007). Jornalismo Digital em Base de Dados (JDBD) - Um paradigma para produtos jornalísticos digitais dinâmicos. (Tese de Doutorado). PósCOM/ UFBA. Available from: http://migre.me/hkrS4 Accessed: 15 de jul. de 2013.

BARBOSA, S. (2008). "Modelo JDBD e o ciberjornalismo de quarta geração". Paper apresentado no GT 7 - Cibercultura y Tendencias de la Prensa en Internet, do III Congreso Internacional de Periodismo en la Red. Foro Web 2.0: Blogs, Wikis, Redes Sociales y e-Participación, Facultad de Periodismo, Universidad Complutense de Madrid (Espanha), 23 e 24 de Abril de 2008.

BARBOSA, S. (2013). "Jornalismo convergente e continuum multimídia na quinta geração do jornalismo nas redes digitais", in CANAVILHAS, J. (Org.). Notícias e mobilidade: o jornalismo na era dos dispositivos móveis. Covilhã, PT: Livros LabCom, pp. 33-54. Available from: http://migre.me/hUrFq. Accessed: 07 set. 2013.

BARBOSA, S.; NORMANDE, N.; ALMEIDA, Y. (2014). "Produção horizontal e narrativas verticais: novos padrões para as narrativas jornalísticas". Trabalho apresentado ao Grupo de Trabalho Estudos de Jornalismo do XXIII Encontro Anual da Compós, na Universidade Federal do Pará, Belém, de 27 a 30 de maio de 2014 .

BARBOSA, S. A.; TORRES, V. (2013) "O paradigma 'Jornalismo Digital em Base de Dados': modos de narrar, formatos e visualização para conteúdos”, in Galaxia, N. ${ }^{\circ}$ 25, São Paulo, pp. 152-164.

BARDOEL, J.; DEUZE, M. (2001). "Network Journalism: Converging Competences of Media Professionals and Professionalism", in Australian Journalism Review 23 (2), pp.91-103. 
BERTOCCHI, D., CAMARGOS, I.O., \& SILVEIRA, S.C. (2015). "Possibilidades narrativas em dispositivos móveis" in CANAVILHAS, J.; SATUF, I. (Orgs.). Jornalismo para dispositivos móveis: produção, distribuição e consumo. Covilhã: Livros LabCom. BOLTER, J. D., \& GRUSIN, R. (2000). Remediation: understanding new media. Cambridge, MA: MIT Press.

BRADSHAW, P.; R. L (2012). The Online Journalism Handbook. Skills to survive in the digital age. Harlow: Pearson.

BROWN, E., \& CAIRNS, P. (2004). "A grounded investigation of game immersion", in CHI'04 - Conference on Human Factors in Computing Systems, Viena/Nova York: ACM Press.

CABrera GONZÁlez, M. A. (2000). "Convivencia de la prensa escrita y la prensa on line en su transición hacia el modelo de comunicación multimédia”, Available from: <http://www.ucm.es/info/periol/Period_I/EMP/Numer_07/74-Comu/7-4-01.htm> Accessed 15 Mai 2013

CANAVILHAS, J. $\left(2014^{\mathrm{a}}\right)$. "A reportagem paralaxe como marca de diferenciação da web”, in REQUEIJO REY, P. y GAONA PISONERO, C. (2014). Contenidos innovadores en la Universidad Actual. Madrid: McGraw-Hill Education, pp. 119-129.

CANAVILHAS, J. $\left(2014^{\mathrm{b}}\right)$. "Hipertextualidade: novas arquiteturas noticiosas", in CANAVILHAS, J. (Org.) Webjornalismo: 7 caraterísticas que marcam a diferença. Covilhã: Livros LabCom, pp. 3-24.

CANAVILHAS, J. (2011). "El nuevo ecosistema mediático", in Index.comunicación, 1, pp. 13-24.

CANAVILHAS, J. \& BACCIN, A. (2015). "Contextualização de reportagens hipermídia: narrativa e imersão" in Brazilian Journalism Research, v.11, n. 1.

CANAVILHAS, J., \& SATUF, I. (2013). "Jornalismo em transição do papel para o tablet... ao final da tarde", in FidAlgO, A. \& CANAVILHAS, J. (Eds.). Comunicação digital: 10 anos de investigação. Coimbra: MinervaCoimbra, pp. 35-60.

DE LA PEÑA, N.; WEIL, P.; LLOBERA, J.; GIANNOPOULOS, E.; POMÉS, A.; SPANLANG, B.; SLATER, M. (2010). "Immersive Journalism: Immersive Virtual Reality for the First-Person Experience of News", in Presence, 19 (4), pp. 291- 301.

DEUZE, M. (2012). Media life. Cambridge: Polity Press. 
DOWLING, D.; VOGAN, T. (2014). "Can we 'Snowfall' this? Digital longform and the race for the tablet market", in Digital Journalism. Epub: 25 mai 2015. DOI:10. 1080/21670811.2014.930250.

FERRARI, P. (2003). Jornalismo digital. São Paulo: Contexto.

FIDLER, R. (1997). Mediamorphosis: understanding new media. Thousand Oaks: Pine Forge Press.

FONTCUBERTA, M., \& BORRAT, H. (2006). Periódicos: sistemas complejos, narradores em interacción. Buenos Aires: La Crujía.

GARRISON, B. (2009). "Online Newspaper”, in SALWEN, M.; GARRISON, B.; DRISCOLL, P. (Orgs.). Online News and the Public. New Jersey: Lawrence Erlbaum Associates, pp. 3-46. INNIS, H. (2011). O viés da comunicação (L.C. Martino, Trad.). Petrópolis, Brasil: Vozes. (Original publicado em 1951)

JACOBSON, S.; MARINO, J.; GUTSCHE JR, R. (2015). "The digital animation of literary journalism”, in Journalism (online). doi:10.1177/1464884914568079

JENKINS, H. (2006). Convergence culture: where old and new media collide. New York: New York University Press.

KATZ, J. (2001). Net: Now Our Most Serious News Medium? Slashot 2001. Available from: <http://features.slashdot.org/story/01/10/05/1643224/net-now-our-most-serious-news-medium>

LANDOW, G. (1997). Teoría del hipertexto. Barcelona: Paidós.

LANDOW, G. (2009). Hipertexto 3.0: teoría crítica y nuevos medios en la era de la globalización. Barcelona: Paidós.

LARRONDO, A.; MIELNICZUK, L.; BARBOSA, S. (2008) "Narrativa jornalística e base de dados: discussão preliminar sobre gêneros textuais no ciberjornalismo de quarta geração", in Anais VI Encontro Nacional de Pesquisadores em Jornalismo (SBPJor). São Bernardo do Campo/SP.

LIMA, E. (2014). "Storytelling em plataforma impressa e digital: contribuição potencial do jornalismo literário", in Revista Organicom, 11: 20, pp. 118-127.

LONGHI, R. (2014). "O turning point da grande reportagem multimídia", in Revista FAMECOS (Online), v. 21, n. 3, pp. 897-917.

LONGHI, R. (2015). "O lugar do longform no jornalismo online. Qualidade versus quantidade e algumas considerações sobre o consumo", in $24^{\circ}$ Encontro 
Nacional da Compós - Associação Nacional dos Programas de Pós-Graduação em Comunicação, Brasília, Universidade de Brasília. Available from: <http:// www.compos.org.br/biblioteca/compos-2015-3c242f70-9168-4dfd-ba4c-0b444ac7347b_2852.pdf> Accessed: 25 jun 2015

MACHADO, E. (2006). OJornalismo Digital em Base de Dados. Florianópolis: Calandra.

MALINI, F. (2009). "Por uma genealogia da Blogosfera: considerações históricas (1997-2001)", in Lugar Comum, n. 23-24.

MANOVICH, L. (2006). El lenguaje de los nuevos medios de comunicación: la imagen en la era digital. Barcelona: Paidós Comunicación.

MCLUHAN, M. (1990). Os meios de comunicação como extensões do homem (understanding media) (D. Pignatari, Trad.). São Paulo, Brasil: Cultrix. (Original publicado em 1964)

MEDINA, C.; LEANDRO, P. (1973). A arte de tecer o presente: (jornalismo interpretativo). São Paulo: Média.

MEYROWITZ, J. (1994). "Medium theory", in CROWLEY, D. \& MICHELL, D. (Eds.). Communication Theory Today. Cambridge: Stanford University Press, pp. $50-77$.

MIELNICZUK, L. (2003). Jornalismo na Web: uma contribuição para o estudo do formato da notícia na escrita hipertextual. (Tese de doutorado). FACOM/ UFBA, Salvador. Available from: <https://repositorio.ufba.br/ri/handle/ri/6057> Accessed 03 abr. 2012.

MIELNICZUK, L.; BACCIN, A.; SOUSA, M.; LEÃO, C. (2015). "A reportagem hipermídia em revistas digitais móveis", in CANAVILHAS, J.; SATUF, I. (Org.). Jornalismo para dispositivos móveis: produção, distribuição e consumo. Covilhã: Livros LabCom.

MIGOWSKI, A. (2013). Memórias coletivas na comunicação mediada por computador : uma análise à luz do acontecimento de 11 de setembro de 2001 em seu décimo aniversário. (Dissertação de mestrado). Porto Alegre, FABICO/UFRGS. Available from: http://www.lume.ufrgs.br/bitstream/handle/10183/76136/000892128.pdf?sequence=1 Accessed: 06 jun 2015

MURRAY, J. (2003). Hamlet no Holodeck: o futuro da narrativa no ciberespaço. (E K Daher \& M F Cuzziol, Trad.). São Paulo: Itaú Cultural: Unesp. 
NEVEU, E. (2014). "Revisiting Narrative Journalism as One of The Futures of Journalism", in Journalism Studies, 15:5, 533-542, doi: 10.1080/1461670X.2014.885683

PALACIOS, M. (2002). Jornalismo online, informação e memória: apontamentos para debate. Available from: http://www.facom.ufba.br/jol/producao.htm. >. Accessed em 12 mai 2013 .

PAVLIK, J. (2005). El periodismo y los nuevos medios de comunicación. Barcelona: Paidós.

PRIMO, A. (2007). Interação mediada por computador. Porto Alegre: Sulina.

PRYOR, L. (2002). The third wave of online journalism. Online Journalism Review. Available from: <http://www.ojr.org/ojr/future/1019174689.php>. Accessed 08 out. 2013 .

RYAN, M-L. (2004). La narración como realidad virtual: la inmersión y la interactividad en la literatura y en los medios electrónicos. Barcelona: Paidós.

SHARP, N. (2013). The future of longform. The Columbia Journalism Review, 9 December. Available from: <http://www.cjr.org/behind_the_news/longform_ conference.php> Accessed 14 mai 2015.

SCOLARI, C. (2013). "Media evolution: emergence, dominance, survival, and extinction in the media ecology", in International Journal of Communication, 7, pp. 1418-1441.

SULliVAN, M (2013). Who gets to 'Snow Fall' or 'Jockey' at the Times and why? New York Times, 20 August 2013. Available from:<http://publiceditor.blogs.nytimes.com/2013/08/20/who-getsto-snow-fall-or-jockey-at-the-times-and-why/> Accessed: 14 mai 2015.

TENORE, M. (2014). "Longform journalism morphs in print as it finds a new home online”. Available from: http://migre.me/oJkre. Accessed 15 jun 2015.

TURKLE, S. (1995). Life on the screen : identity in the age of the Internet. New York: Simon \& Schuster.

ZELIZER, B.; ALLAN, S. (2002). Journalism After September 11. London: Routledge. 